\title{
A reply to 'Science versus vernacular': should some taxa of animals and plants be renamed according to 'indigenous' practices?
}

\author{
Len Norman GILLMAN* \& Shane Donald WrighT** \\ * rone Lab, Faculty of Design and Creative Technology, Auckland University of Technology, St Paul Street, Auckland, \\ 1010, New Zealand. \\ ”len.gillman@aut.ac.nz. @ ittps://orcid.org/0000-0002-2283-495X \\ **School of Biological Sciences, University of Auckland, Symonds Street, Auckland, 1010, New Zealand. \\ ڤ"sd.wright@auckland.ac.nz. @ https://orcid.org/0000-0003-2655-5576
}

\begin{abstract}
Palma \& Heath (2021) have recently commented on our proposal to reinstate indigenous names within the Linnaean system of nomenclature on the basis of their chronological priority. They argue that this challenges rules that have been unquestioned for 250 years. However, we hold that the rules of the various codes of nomenclature are constantly under review. The opinion they prosecute crystallises down, in large part, to one that suggests that because there are pre-existing rules about priority, we should not change these: an argument that involves a degree of circularity. Unfortunately, Palma and Heath misinterpret our proposal throughout much of their discussion. We do not advocate replacing the binomina as is claimed nor do we advocate for name changes where there is no consensus on a given taxon among the people indigenous to the natural distribution of that taxon. Our proposal is that indigenous names can replace the species epithet where there is a consensus on a single indigenous name for a taxon throughout its distribution and where there is demonstrable temporal priority. Without such consensus, species that cover wide distributions and have multiple indigenous names will, under our proposal, remain unchanged in their nomenclature.
\end{abstract}

\section{Key words}

Binomina, chronological priority, Indigenous names, Indigenous Peoples.

\section{Introduction}

Palma \& Heath (2021) point out that an earlier comment on our proposal was rejected by Communications Biology. Another comment was withdrawn and a third in support of our proposal was also rejected. We submitted replies to these comments and were disappointed when the full debate was not published. However, we do not think it is appropriate to accuse those editors of "stifling opinion" when decisions do not go the way we might hope. Here we counter the arguments put forward by Palma \& Heath under each of the headings they used. 


\section{Restoring 'indigenous' names in taxonomy}

It is claimed that we "posited that there is no difference in nature between vernacular (common, local or trivial) names of animals and plants, and scientific names (nomina) [...]" However, we have made no such statement; that there are clear differences between these categories is actually immaterial to our proposal. Their argument that indigenous names are "not in any way based on attempts to understand the relationships between organisms or their evolution" also applies to all species epithets under the current rules. For example, the surname derived species epithet 'solandri' does not in any way indicate an understanding of "relationships between organisms or their evolution". Evolutionary relationships only become apparent when the genus is included in the binomen, such as for Nothofagus solandri (Hook. f.) Oerst. or Olearia solandri (Hook. f.) Hook. f. The same apparent evolutionary relationship, that is afforded by the binomen to produce Nothofagus solandri, would also be apparent if the species epithet were to be replaced by the prior indigenous 'tâwhairauriki' to become Nothofagus tawhairauriki.

Palma \& Heath raise the issue that "different names may be given to different members of the same biological species" despite it being clear in our original proposal that there can be no name change under such circumstances. We instead stated, "where different groups of Indigenous Peoples are unable to form a consensus over the name for a particular taxon then no indigenous name would have status and the taxon name would remain unchanged" (Gillman \& Wright 2020).

Palma \& Heath continue: "in contrast, the same name may be given to different species [...]". However, one of the very reasons for the binomen is that, if the generic identities of two species with the same specific epithet are different, then there is no issue with two binomina sharing that same species epithet, as per the example we give above for solandri. If the same indigenous name applies to more than one species of the same genus then our proposal is clear that such identical binomina will not be accepted. Both of these situations were covered in our original publication and reiterated in subsequent discourse. It is concerning to us that Palma \& Heath and others continue to erect these points of issue despite our clear statements on these matters.

\section{Science undermined}

It is claimed that we "underrated or even denied the scientific discipline of biological taxonomy" and our proposal "[...] is a frontal attack on the scientific discipline of biological taxonomy." We have to counter that the "scientific discipline" itself and the process of describing taxa would remain undamaged under our proposal. Only the name applied to one component of the entire systematic and hierarchical structure might be replaced and then only on the basis of its demonstrable chronological priority. Palma \& Heath thus confuse the application of a name-which may for example be simply based on a surname and often is - with the science of description and enquiry into ecological and evolutionary relationships.

They continue: "They also overlooked the point [...] that only a very small proportion of the biota in any territory occupied by native peoples will be given identifying names" (Palma \& Heath 2021). However, we explicitly stated that "the number of taxa across the globe that could be considered for such retrospective name changes will be limited". Palma \& Heath (2021) have misinterpreted our clearly enunciated text. 


\section{Rules of nomenclature}

In terms of their claim of a "paternalistic gesture" on our part; we respectfully request that in this contest of ideas we together avoid denigration of the perceived motives of fellow scientists. Palma $\&$ Heath also suggest that the use of indigenous names in scientific nomenclature "would mean lack of comprehension for users outside of the countries involved, and so goes counter to the universality, utility and explanatory power of science". Nonetheless, they give examples where indigenous names have already been applied without any apparent adverse impact on understanding. Furthermore, understanding the meaning of a species epithet is not of itself a necessary component to ecological or evolutionary understanding. In fact, such an awareness of etiology can be misleading, such as in the case of Griselinia littoralis (Raoul) Raoul, 1846 - a species not only found in the littoral zone, but which is distributed all the way up to the treeline, and even into the subalpine, in Aotearoa.

"Thus, Gillman \& Wright (2020) showed that they have no idea of what the concept of 'nomenclatural availability' of nomina is." We beg to differ. We are indeed proposing a change to the rules relating to nomenclatural availability based on a transparent understanding of such relationships on our part. To simply restate the existing rules and accuse us of having "no idea" of a concept demonstrates a failure to accurately elucidate and challenge the proposed change.

Finally, under this section, the allocation of type specimens for species that undergo a name change is raised. In a detailed proposal of rule changes to the International Code of Nomenclature for algae, plants and fungi (ICN) (Turland et al. 2018), we have suggested (Wright \& Gillman, 2021) that a similar process is followed to that when a genus is disestablished and two are then merged. In that case any shared species epithets naturally require the establishment of a new species name. In these cases, under the $I C N$, the pre-existing type specimen for the altered species name is applied to the new species binomen.

\section{Principle of priority}

We do not seek to declare "the Principle of Priority void" as suggested by Palma \& Heath; we instead propose to change the rules such that they apply chronological priority to long-standing indigenous names where this can be formally demonstrated. We therefore take the view that we are in fact contributing to the rigour of the principle of priority with our suggested rule changes. There were two reasons given under this heading as to why our rule change is impractical: [1] it is important that priority of publication is understood by everybody, especially when "a taxon has a wide geographic distribution"; [2] "it would be a great dilemma which of the many 'indigenous' names to choose. This, to our minds, is one of the biggest problems posed by Gillman \& Wright's (2020) suggestion". Again, as outlined in our original proposal, where there are multiple names and no consensus across the distribution of a given taxon there will be no change. In reference to their first point, a consensus among the relevant Indigenous Peoples for a name of a taxon covering the area of its natural distribution is not in our opinion a concept that is too difficult to understand. We reiterate the point that taxa with wide distributions may not be known by a single indigenous name and will therefore not be candidates for a name change under our proposal without such consensus. Likewise, where there is no indigenous name there will be no name change and so we fail to see why Palma \& Heath see this as a problem. 


\section{Communication value of nomenclature}

We agree that "unambiguous and universally accepted nomenclatural rules" are required for nomenclature and communication. We merely seek to modify these rules using a strong and clearly interpretable universal principal of chronological priority - one that is already a central conceptual tenet in the science of taxonomy.

\section{Are vernacular names valid?}

Palma \& Heath assert that indigenous names and scientific names belong in different realms. We contend that there is no reason why that should be so and, indeed, to imply so is demonstrably false since indigenous names have already been used widely in binomina. Indigenous names can of course be applied within the Linnaean hierarchical system without disrupting the system. For example, the tree species Beilschmiedia tawa (A. Cunn.) Benth. et Hook. f. ex Kirk includes an unadulterated indigenous name from Aotearoa. Many other examples are given by Rummy \& Rummy (2021). Surely if we are to consider names that are inherently unscientific we should look to the overwhelming use of the surname in binomina as an example of that limitation.

\section{What does 'indigenous' mean?}

There is little confusion about the meaning of Indigenous Peoples. The narrow application of the term in a biological sense by Palma \& Heath to entities that have evolved in their current location is not appropriate when applied to people. A precise definition of Indigenous Peoples is also not required because the framework we propose does not rely on a definition. Instead, the framework of our proposal is built on the proposed rule that the indigenous name is that with earliest priority for the taxon. Species spanning multiple peoples with multiple languages will not qualify for a name change. Therefore, a European name could qualify if it was endemic to a single language and has a single name with chronological priority.

\section{Problems with terminological imprecision}

They go on: "Accusations of 'cultural appropriation' are often levelled at those who would adopt names without consultation with the 'owners' [...]. Gillman \& Wright (2020) did not consider these possibilities, but if they were to do so, they would need to do ethnographic research beforehand, and it is likely that protracted discussions would be required in order to reach a consensus as to an agreed epithet." We are left a little non-plussed by these claims. We do not propose to rename anythingour proposal leaves that to the relevant Indigenous Peoples. Furthermore, our proposal is that those Indigenous Peoples provide both evidence of chronological priority and evidence of a nomenclatural consensus among any competing Indigenous groups. If it is too difficult for them to achieve such an evidential base then there would be no name change. 


\section{Taxonomy and politics}

We disagree that taxonomy and science in general is devoid of politics. Any system stands on the basis of its usefulness and appropriateness within the society it serves. By contrast, systems do not typically survive if they have not changed in 250 years. Taxonomy as a discipline faces major challenges in the $21^{\text {st }}$ century largely around the issue of contemporary relevance. In our view this is a serious matter because all biological sciences rely on taxonomists. As the needs and expectations of society change so must our systems, and this includes a continuing adjustment and development of nomenclatural rules to ensure relevance in a more dynamic contemporary setting.

\section{References}

Gillman, L. N. \& Wright, S. D. (2020) Restoring indigenous names in taxonomy. Communications Biology, 3 (1) [609]: 1-3. <https://doi.org/10.1038/s42003-020-01344-y>.

Palma, R. L. \& Heath, A. C. (2021) Science versus vernacular: should some taxa of animals and plants be renamed according to 'indigenous' practices? Bionomina, 22: 1-7. $<$ https://doi.org/10.11646/bionomina.22.1.1>.

Rummy, P. \& Rummy, J. T. (2021) Recontextualising the style of naming in nomenclature. Humanities and social Sciences Communications, 8 (1) [283]: 1-6. <https://doi.org/10.1057/s41599-021-00975-8>.

Turland, N. J., Wiersema, J. H., Barrie, F. R., Greuter, W., Hawksworth, D. L., Herendeen, P. S., Knapp, S., Kusber, W.-H., Li, D.-Z., Marhold, K., May, T. W., McNeill, J., Monro, A. M., Prado, J., Price, M. J. \& Smith, G. F. (ed.) (2018) International code of nomenclature for algae, fungi, and plants (Shenzhen Code) adopted by the Nineteenth International Botanical Congress Shenzhen, China, July 2017. Regnum Vegetabile, 159. Glashütten, Germany (Koeltz Botanical Books). <https://doi.org/10.12705/Code.2018>.

Wright, S. D. \& Gillman, L. N. (2021) Replacing current nomenclature with pre-existing indigenous names in algae, fungi and plants. Taxon, in press. <https://doi.org/https://doi.org/10.1002/tax.12599>.

Submitted: 23 November 2021. Accepted: $1^{\text {st }}$ December 2021. Published: 17 December 2021.

Corresponding Editor: Alain Dubois. 